\title{
Christian Starck, Woher kommt das Recht?
}

\section{Audrey Dauchy}

\section{OpenEdition \\ Journals}

Édition électronique

URL : http://journals.openedition.org/ifha/8575

DOI : $10.4000 /$ ifha. 8575

ISSN : 2198-8943

Éditeur

IFRA - Institut franco-allemand (sciences historiques et sociales)

\section{Référence électronique}

Audrey Dauchy, "Christian Starck, Woher kommt das Recht? », Revue de I'IFHA [En ligne], Date de recension, mis en ligne le 01 février 2017, consulté le 24 septembre 2020. URL : http:// journals.openedition.org/ifha/8575; DOI : https://doi.org/10.4000/ifha.8575

Ce document a été généré automatiquement le 24 septembre 2020.

(CIFHA 


\title{
Christian Starck, Woher kommt das Recht?
}

\author{
Audrey Dauchy
}

\section{RÉFÉRENCE}

Christian Starck, Woher kommt das Recht?, Tübingen: Mohr Siebeck, 2015, XIV-400 p., $59 €$ 
D'où vient le droit? Cette question essentielle guide l'ensemble des textes de cet ouvrage, principalement constitué d'articles de Christian Starck parus depuis 2000. La contribution éponyme de 2009 et la collection de 24 articles regroupés sous trois titres thématiques renvoient à cette interrogation appelant des réponses multiples et font accéder à une compréhension globale de l'enseignement de l'auteur, professeur émérite de droit public de l'université de Göttingen. Des répétitions se logent inévitablement dans ce corpus de textes édités dans leur version originale, ce dont le lecteur est par ailleurs averti dès l'introduction. Il faut cependant souligner que la construction du livre en chapitres spécialisés offre la possibilité d'orienter la lecture au gré de centres d'intérêts particuliers.

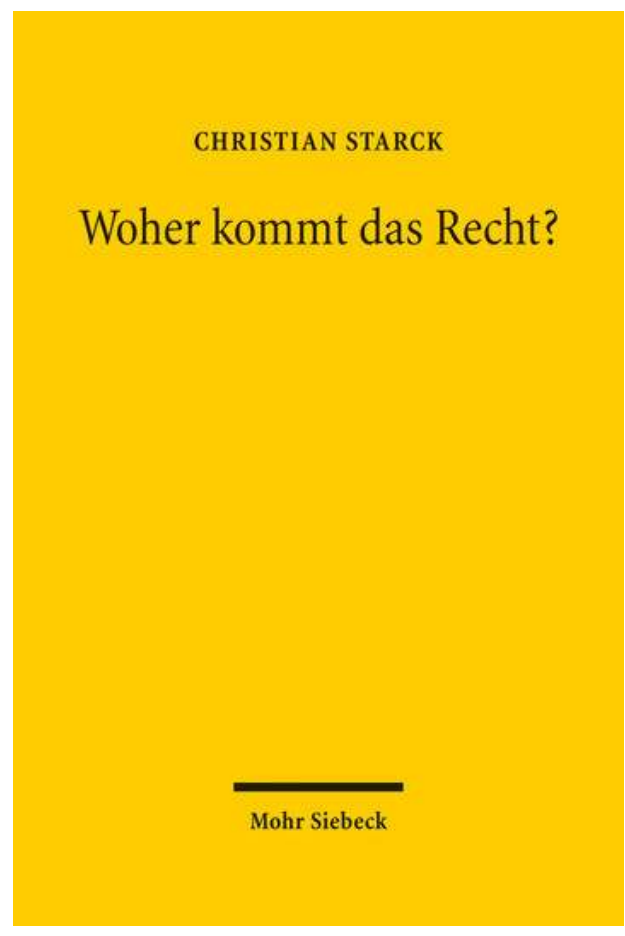

La question de l'origine du droit n'est évidemment pas épuisée par la réponse formelle de sa nature étatique ou contractuelle, ce qui est précisé dès les premières pages, même si cet aspect est amplement développé, en particulier sous l'angle des relations entre le droit public et le droit privé et de la capacité des personnes privées à produire du droit. Le lecteur trouvera dans ces différentes contributions l'exposition de fondements juridiques, historiques et philosophiques de principes généraux de droit public, dans une perspective d'analyse comparée du droit allemand contemporain. Il est à noter que les droits supranationaux - droit européen et droit international - occupent également une place importante dans cet ouvrage.

Dans une première partie consacrée aux notions de loi et de droit, C. Starck revient sur la nature de la loi et le processus législatif, retient les cas problématiques d'application de la loi faisant écho au débat sur son efficacité, rend compte de la relation hiérarchique entre la norme constitutionnelle et la norme légale, et s'attache à décrire la composante contractuelle de la législation. Un article porte sur l'évolution des rapports entre la loi et le droit. L'auteur y rappelle la nécessité d'une autorité supérieure à celle du législateur, qui s'exprime aujourd'hui dans les constitutions, et retrace l'histoire de ce droit supérieur sans omettre les errements auxquels son absence a pu conduire. La deuxième partie se penche sur les contours historiques de la notion de droits fondamentaux et aborde certaines questions pratiques qui lui sont rattachées, telles que celles de l'égalité entre hommes et femmes, de la dignité humaine et de la bioéthique ou encore de la législation relative à l'assurance sociale. Ces chapitres de droit appliqué témoignent d'une parfaite maîtrise des terminologies et des procédures propres à ces spécialités et en constituent d'excellentes introductions. On peut toutefois regretter que le sujet de l'égalité des droits entre hommes et femmes soit presque exclusivement envisagé du point de vue du droit allemand. La culture juridique constitue enfin le nerf de la troisième partie, dans laquelle sont traités des points aussi 
divers que la liberté, la légitimité de la souveraineté étatique résidant dans la capacité de l'État à protéger la liberté et à défendre la paix, les formes de transfert juridique, la hiérarchie des normes entre le droit international public, le droit européen et le droit constitutionnel des États, et enfin l'harmonisation juridique d'un espace donné. L'ultime chapitre, reprenant un article de 2002 sur l'avenir de la recherche en droit, relève à juste titre la nécessaire prise en compte de la mondialisation ainsi que de l'influence croissante de l'individualisme et de l'utilitarisme. Dans cet article qui reste d'actualité, Christian Starck souligne que seule une parfaite connaissance du droit et de ses fondements permet de se saisir de ces réalités pour trouver des solutions adaptées.

Le titre ouvert de cette compilation ne doit occulter ni l'aspect technique qu'elle revêt indéniablement, les principes de droit public étant au cœur de toutes les contributions, ni l'éclairage prioritairement allemand et européen de son propos. Cela posé, l'ouvrage permet d'aborder et d'approfondir les théories régissant les relations entre les différentes normes de droit dans une perspective dépassant la seule Allemagne, tout en rendant le droit public allemand accessible aux non-initiés. Surtout, il donne matière à réflexion sur des notions transcendant une approche purement juridique - droit, loi, droits fondamentaux, liberté - auxquelles ce livre fait pleinement honneur.

INDEX

Thèmes : Histoire des États et des pouvoirs, Histoire du droit, Histoire des idées

Index chronologique : Ouvrage transpériodique

\section{AUTEURS}

\section{AUDREY DAUCHY}

Université Panthéon-Assas Paris II, Johann Wolfgang Goethe-Universität (Frankfurt am Main) Institut Franco-Allemand/Sciences Historiques et Sociales (IFRA/SHS) 